\title{
LA POLÍtica EN EDUCACión Como DETERMINANTE DE DESARROLLO ECONÓMICO: EL CONTEXTO HISTÓRICO SOBRE LA TENSIÓN DE MODELOS ECONÓMICOS (I)
}

\author{
PUBLIC POLICY IN EDUCATION \\ AS A FACTOR OF ECONOMIC \\ DEVELOPMENT: THE ECONOMIC \\ TENSION BETWEEN DEVELOPMENT \\ MODEL AND GROWTH MODEL (I)*
}

\author{
Luis Ricardo Gómez Pinto** \\ Fecha de recepción: 12 de noviembre de 2013 \\ Fecha de aprobación: 20 de diciembre de 2013 \\ Disponible en línea: 30 de junio de 2014
}

\section{Para citar este artículo / To cite this article}

Luis Ricardo Gómez Pinto, La política en educación como determinante de desarrollo económico: El contexto histórico sobre la tensión de modelos económicos, 128 Vniversitas (2014). http://dx.doi.org/10.11144/Javeriana. VJ128.pecd

doi:10.11144/Javeriana.VJ128.pecd

Este artículo está dedicado a la memoria de los profesores Naty Pinto Afanador y Diego Castro, cuyo espíritu acompañó estas palabras.

* Este artículo comprende una primera y una segunda parte de la investigación realizada por el autor en el Grupo de Investigación de Derecho Público de la Pontificia Universidad Javeriana. Este trabajo surge en la línea de investigación sobre política pública en el derecho social a la educación y desarrollo económico.

** Abogado de la Pontificia Universidad Javeriana, especialista en Derecho Sustantivo y Contencioso Constitucional y Magíster en Derecho Económico. Profesor de Derecho Económico en la Facultad de Ciencias Jurídicas de la Pontificia Universidad Javeriana y miembro del grupo de investigación de Derecho Público en la misma facultad.

Correo electrónico:1.gomezp@javeriana.edu.co 


\section{RESUMEN}

La presente investigación gira en torno al interrogante: ¿cómo puede la educación modificar las perspectivas de vida en una sociedad? El presente artículo propone un recuento histórico del estado del arte de la educación en Colombia y abordará el problema sobre la concepción de su naturaleza. A partir de aquí, se dejarán planteadas unas conclusiones acerca del contexto histórico de la educación como política pública.

Palabras clave: derecho social a la educación; economía liberal; economía social de mercado; modelo de desarrollo; crecimiento económico; bienes y servicios esenciales; economía liberal; modelo intervencionista; Amartya Sen 


\section{ABSTRACT}

This study comes from the research question: How society's perspectives of life can be modified by education? The present article proposes a historical account and a state of the art of education in Colombia. It also approaches the problems derived from the conception of its nature. From this point, some conclusions about the historical context of education as a public policy will be raised.

Keywords: right to education; liberal economy; social economy; development economy; economic welfare; social rights; Amartya Sen

\section{SUMARIO}

INTRODUCCIÓN. LA ECONOMÍA, LA EDUCACIÓN Y FRANKENSTEIN EN LAS CRISIS MODERNAS.- I. RECONSTRUCCIÓN HISTÓRICA DE LA POLÍTICA ECONÓMICA EN COLOMBIA.- A. Discusiones sobre crecimiento y desarrollo en el modelo económico del siglo XX. 1936-2013.- B. Un periodo coyuntural en la política económica para finales del siglo XX: la Constitución de 1991 y la educación en la economía social de mercado.- 1. La última década del siglo XX.- 2. Las reformas constitucionales en los primeros años del siglo XXI: la financiación del modelo educativo y el regreso al esquema neoliberal.- $C$. Contextualizando el problema: Algunas consideraciones sobre la educación en la Constitución de 1991 y el dilema entre el servicio público y el derecho social.- PARA CONCLUIR. 


\section{INTRODUCCIÓN. LA ECONOMíA, LA EDUCACIÓN Y FRANKENSTEIN EN LAS CRISIS MODERNAS}

La primera década del siglo XXI en Colombia, y en gran parte de Latinoamérica, muestra indicadores de acceso limitado a servicios públicos esenciales y mercados de bienes. Las realidades de segregación económica y discriminación social son las barreras más grandes que enfrenta la noción de libertad. Para este momento (2013) en Colombia el $44 \%$ de la población es pobre; el 12\% de ese total se encuentra en estado de indigencia o pobreza extrema; alrededor de 374.000 niños y niñas no asisten a la escuela; el 15\% de mujeres no tiene acceso a fuentes de trabajo, y el $2 \%$ de las mujeres entre los 15 y 24 años es analfabeta. Bajo estas condiciones inaceptables ningún significado de libertad puede ser concebido.

En respuesta a lo que parece ser un fenómeno de crisis globalizada, la idea de libertad ha venido ganando terreno en la teoría económica. Amartya Sen, en este sentido, describirá que para que el hombre sea verdaderamente libre ha de conquistar el acceso pleno a los mercados y satisfacer sus necesidades. Sen entiende la libertad como la posibilidad de optar, sin ataduras o condiciones infrahumanas, por un proyecto digno de vida. Se trata de un concepto de libertad en el sentido que proponía Rawls. Siendo así guiados de la mano de Sen, vamos a describir y reconstruir la noción de educación como una variable de desarrollo en el sentido de una muy importante herramienta de cambio para crear oportunidades de inclusión, reducción de pobreza, hambre y desolación social. Al respecto, para la primera década del siglo XXI, la educación se convierte en un determinante de libertad en las sociedades modernas. En los países con mayores niveles de cobertura y cubrimiento en educación de calidad en el mundo, tales como Finlandia, Corea del Sur, Israel, Costa Rica, se alcanzan los mayores niveles de desarrollo - lo que no necesariamente representa condiciones de crecimiento económico- $\mathrm{y}$, por lo tanto, mejores condiciones para el ejercicio de los derechos. 
Siendo así, la propuesta del presente trabajo se articula de la siguiente manera. En una primera parte, se hace una reconstrucción histórica sobre el estado de cosas de la educación, dentro de la evolución que la política económica ha tenido en Colombia, iniciando en la reforma social y constitucional de 1936 hasta los modelos de gobierno en la primera década del siglo XXI. Esta muestra permite encontrar avances, como el de 1936, y retrocesos, como las políticas restrictivas de gasto e inversión en educación, en la manera de diseñar la política pública en educación.

En la segunda parte se abordará el problema sobre la naturaleza de la educación, partiendo de la dicotomía que plantea la Constitución respecto a la noción de derecho social fundamental y servicio público esencial. ¿Se trata de un bien público que responde a las características clásicas de no exclusión y no rivalidad? Todo parecería indicar que se trata de un bien que se comporta a modo de una externalidad positiva. Sin embargo, Sen no creerá esto.

Finalmente, se propondrán, a modo de reflexión, algunas conclusiones que servirán de marco de trabajo para lo que se planteará en la segunda parte de la investigación.

\section{RECONSTRUCCIÓN HISTÓRICA DE LA POLÍTICA ECONÓMICA EN COLOMBIA}

\section{A. Discusiones sobre crecimiento y desarrollo en el modelo económico del siglo XX. 1936-2013}

\begin{tabular}{|c|c|c|}
\hline Periodo & Nacional & Internacional \\
\hline 1930-1936 & $\begin{array}{l}\text { Auge de los mercados libres. } \\
\text { La crisis en un momento ini- } \\
\text { cial no afectó a los mercados } \\
\text { en Colombia }{ }^{1} \text {. Periodo de } \\
\text { fortalecimiento de la Uni- } \\
\text { versidad Nacional. }\end{array}$ & $\begin{array}{l}\text { Crisis del Estado liberal y su } \\
\text { modelo de economía clásica. } \\
\text { Los sectores más débiles y } \\
\text { aislados de la política econó- } \\
\text { mica son los más afectados } \\
\text { (salud, educación, trabajo, } \\
\text { seguridad social). }\end{array}$ \\
\hline
\end{tabular}

1 Salomón Kalmanovitz, Economía y nación. Una breve historia de Colombia, Norma, Bogotá, 305 (2003). 


\begin{tabular}{|c|c|c|}
\hline Periodo & Nacional & Internacional \\
\hline $1936-1950$ & $\begin{array}{l}\text { Crisis de la economía co- } \\
\text { lombiana. Periodo de pro- } \\
\text { teccionismo económico con } \\
\text { modelos de cierre de fronte- } \\
\text { ras y sustitución de impor- } \\
\text { taciones. Reforma educativa } \\
\text { y creación de la ciudad uni- } \\
\text { versitaria en la Universidad } \\
\text { Nacional. Apertura de fa- } \\
\text { cultades de educación y de } \\
\text { nuevos modelos educativos. } \\
\text { Adopción del modelo inter- } \\
\text { vencionista pensando en un } \\
\text { modelo de crecimiento de } \\
\text { la economía, desde la ópti- } \\
\text { ca de un modelo social de } \\
\text { mercado. Reformas sociales } \\
\text { y constitucionales de } 1936 \\
\text { y } 1945 \text {. }\end{array}$ & $\begin{array}{l}\text { Efectos relevantes de la po- } \\
\text { lítica keynesiana: recons- } \\
\text { trucción de Europa en la } \\
\text { posguerra (1939-1945). Mo- } \\
\text { delo de empoderamiento de } \\
\text { las políticas fiscales de los } \\
\text { gobiernos. Fortalecimiento } \\
\text { de la demanda agregada } \\
\text { como variable para el for- } \\
\text { talecimiento económico. } \\
\text { Expansión de los mode- } \\
\text { los constitucionales que se } \\
\text { amparan en la cláusula del } \\
\text { Estado social de derecho } \\
\text { (Alemania, España, Italia). } \\
\text { Cierre de las relaciones eco- } \\
\text { nómicas entre los Estados } \\
\text { con el fin de adoptar mode- } \\
\text { los proteccionistas de econo- } \\
\text { mía hacia adentro. }\end{array}$ \\
\hline $1950-1957$ & $\begin{array}{l}\text { Inicio del régimen conser- } \\
\text { vador de Laureano Gómez. } \\
\text { Congelamiento de las rela- } \\
\text { ciones entre el Estado y la } \\
\text { Universidad Nacional. For- } \\
\text { talecimiento de la relación } \\
\text { entre Iglesia y Estado como } \\
\text { punto de referencia para la } \\
\text { implantación de un modelo } \\
\text { educativo nacional. }\end{array}$ & $\begin{array}{l}\text { Rezagos de la política key- } \\
\text { nesiana. Diseño de políticas } \\
\text { intervencionistas por parte } \\
\text { de los Estados. Auge de } \\
\text { las economías asiáticas, en } \\
\text { especial por el proceso de } \\
\text { expansión y desarrollo del } \\
\text { Japón }{ }^{2} \text {, potencia mundial } \\
\text { hasta el momento. Guerra } \\
\text { de Corea e inicio del con- } \\
\text { texto de la Guerra Fría y la } \\
\text { tensión entre comunismo y } \\
\text { capitalismo. }\end{array}$ \\
\hline
\end{tabular}

2 Cfr. Ugo Pipitone, Ciudades, naciones, regiones, Fondo de Cultura Económica, México D.F., 326 (2003). 


\begin{tabular}{|c|c|c|}
\hline Periodo & Nacional & Internacional \\
\hline $1957-1974$ & $\begin{array}{l}\text { Asentamiento del Frente } \\
\text { Nacional. Creación de la } \\
\text { Fundación para la Educa- } \\
\text { ción Superior y el Desarro- } \\
\text { llo (Fedesarrollo). Inicio del } \\
\text { periodo de tecnocratización } \\
\text { administrativa y del derecho. } \\
\text { Ingenieros y economistas de } \\
\text { la élite colombiana formada } \\
\text { en Estados Unidos aparecen } \\
\text { como diseñadores de políticas } \\
\text { públicas } \text {. Influencia del dise- } \\
\text { ño administrativo elaborado } \\
\text { por Estados Unidos y la Fun- } \\
\text { dación Ford. El modelo de } \\
\text { la educación se define por el } \\
\text { mercado de bienes y servicios. } \\
\text { Inicio del proceso de apertura } \\
\text { económica. }\end{array}$ & $\begin{array}{l}\text { Tránsito del desarrollo hacia } \\
\text { adentro al desarrollo hacia } \\
\text { fuera. Fin del "consenso key- } \\
\text { nesiano"4. Periodo de choque } \\
\text { político y militar entre la ex- } \\
\text { presión de los modelos de eco- } \\
\text { nomía clásica representado } \\
\text { en el capitalismo y el modelo } \\
\text { socialista, representado en el } \\
\text { comunismo. } \\
\text { Inicio de la guerra de Vietnam } \\
(1965) \text {. }\end{array}$ \\
\hline 1974-1991 & $\begin{array}{l}\text { Los gobiernos de turno ini- } \\
\text { cian la lucha contra el nar- } \\
\text { cotráfico (López, Turbay). } \\
\text { Asentamiento del proceso de } \\
\text { violencia como consecuencia } \\
\text { del aislamiento de ciertos } \\
\text { sectores sociales que busca- } \\
\text { ban la participación política. } \\
\text { Fortalecimiento de las gue- } \\
\text { rrillas colombianas. Inicio } \\
\text { del proceso de gasto militar } \\
\text { Sustitución del modelo in- } \\
\text { tervencionista por el de libre } \\
\text { mercado. Inicio del proceso } \\
\text { de reformismo orientado a la } \\
\text { sostenibilidad del modelo de } \\
\text { crecimiento económico. }\end{array}$ & $\begin{array}{l}\text { Fortalecimiento de los mode- } \\
\text { los presidenciales bajo el mar- } \\
\text { co económico de programas } \\
\text { neoliberales, básicamente en } \\
\text { los Estados Unidos y el Reino } \\
\text { Unido. } \\
\text { Tensión mundial por la Gue- } \\
\text { rra Fría, entre las economías } \\
\text { de occidente y la cortina de } \\
\text { hierro en Europa oriental. }\end{array}$ \\
\hline
\end{tabular}

3 Cfr. Jairo Estrada, Élites intelectuales y producción de política económica en Colombia, en Jairo Estrada Álvarez, ed., Intelectuales, tecnócratas y reformas neoliberales en América Latina, Universidad Nacional de Colombia, 268 y 342 (2005) (en adelante, Intelectuales).

4 Ibídem, 265

5 El auge de la política neoliberal de mercados, como en el caso referido, tiene su expresión durante uno de los periodos liberales más fuertes. Al respecto, Ugo Pipitone llama la atención sobre este fenómeno político, que marcará la tendencia de algunos procesos económicos y la mayoría de las medidas que se adoptan para conjurar las crisis. Por ejemplo, el caso de los Estados Unidos durante los años sesenta y setenta del siglo pasado, en respuesta a las crisis del petróleo, cuando las ideas progresistas y liberales adoptadas para contrarrestarla fueron lideradas por gobiernos conservadores. Óp. cit., 241. 


\section{Periodo Nacional Internacional}

1991-2013 Aumento del proceso de déficit Contexto de las crisis económifiscal ${ }^{6}$. Tensión de modelos de cas originadas en los mercados crecimiento y desarrollo. Por una financieros en 1998 y 2008, que parte, los mercados siguen sien- se hicieron expansibles por las do el referente para la adjudica- conexiones de los mercados ción de bienestar a la población; globalizados. Crisis del modelo por otra, la Corte Constitucional liberal de mercados y de reducrompe el discurso de economía cionismo de la intervención del y Estado conservador y retorna Estado, en países como España, al concepto de desarrollo en el Italia y Grecia.

escenario de la economía social de mercado.

No se trata de un periodo lineal ${ }^{7}$. Existencia de un proyecto económico de apertura y liberalización de mercados (modelo de crecimiento) que encuentra su contrapeso en el proyecto de progresismo social iniciado por la Corte Constitucional de los años noventa (modelo de desarrollo) ${ }^{8}$. Reducción del gasto público social en materia de cobertura y calidad en educación ${ }^{9}$. Debilitamiento del modelo de descentralización territorial (Actos Legislativos 01 del 2001 y 04 del 2007). Fortalecimiento del modelo de financiación del gasto militar que inició en la década de los setenta. Se incorpora a la Constitución el principio de la sostenibilidad fiscal.

6 Cfr. Cubides Aristizábal \& Jiménez, óp. cit., 329.

7 Cfr. Jairo Estrada, óp. cit., 286.

8 La diferencia entre la noción de desarrollo y crecimiento será relevante para entender los proyectos ideológicos económicos y las políticas que los definen, así como algunas de las razones de por qué estos conceptos, aunque conviven en los discursos económicos, entran permanentemente en tensión. Así lo advierten Diana Aristizábal, Juliana Cubides y Carolina Jiménez en el siguiente texto: "[...] en un principio se consideraron de manera separada los aspectos y objetivos económicos y sociales del desarrollo; sin embargo, con el despliegue de la teoría del capital humano, entre otras estrategias, se empiezan a poner en escena nuevos paradigmas de integración y relación que se afirmaban frente al dominio de las narrativas economicistas, argumentando que el desarrollo no se reducía a altas tasas de crecimiento. Dicho de otro modo, en las décadas siguientes entra en crisis la definición economicista del desarrollo, e inician procesos que intentan armonizar la dimensión económica, con los objetivos más sociales y humanos del desarrollo. En esta dirección, se argumenta la necesidad de integrar al concepto y a las políticas del desarrollo, categorías como calidad de vida, capital humano, equidad social, sustentabilidad ambiental, entre muchos otros". Discursos y narrativas de las reformas estructurales en la élite intelectual colombiana, en: Intelectuales, 325.

Esta definición de desarrollo será definitiva para entender el sentido de la noción que se usa en la presente investigación, y de la cual partiremos como contra parte a la de crecimiento económico que se elaboró en la década de los años setenta y ochenta del siglo XX, a partir de los modelos de economía liberal. Para la primera y segunda década del siglo XXI, estos conceptos reaparecerán como contradictorios en el espectro de la historia económica.

9 Carlos Alberto Lerma Carreño, El derecho a la educación en Colombia, Fondo latinoamericano de políticas educativas, 37 (2007). 
Para la década de los treinta, lo que la economía entiende por modelo de desarrollo tendrá como prioridad garantizar condiciones óptimas de progreso económico. Para esto, el Estado asume la responsabilidad de adelantar proyectos de inversión en gasto social, como lo fue el fomento de proyectos educativos. El fortalecimiento de la Universidad Nacional y la creación de la ciudad universitaria serán la muestra de estos avances en el proceso de expansión y fortalecimiento de la política educativa en Colombia, para los inicios del siglo XX. El auge de este periodo se verá durante 1936-1950, en lo que se refiere a los procesos educativos de formación de profesionales. La tendencia hacia la inversión pública en educación, así como otros proyectos de inversión social, como fue la organización de la universidad pública en el país, se fortaleció en un contexto de reforma económica y social que buscaba generar condiciones de progreso.

Bajo este contexto, la reforma de corte social de 1936 partía de la separación de las relaciones entre el Estado y la Iglesia. Esta reforma trajo consigo la adopción de un modelo laico, que abrió la posibilidad de implantar proyectos educativos de diversas facciones y connotaciones, mientras no se contradijeran los postulados de la Iglesia católica ${ }^{10}$. Mediante esto se creaban oportunidades mínimas de inclusión y espacios de participación en materia religiosa ${ }^{11}$, dando inicio al proceso de reforma del modelo educativo. En este sentido, se modera la postura de la Constitución de 1886 en la relación entre educación y religión. A partir de las políticas públicas integrales y socializadas, aunque todavía limitadas por la fuerza política que representa el movimiento de la Regeneración en la Constitución de 1886, se abre la posibilidad para garantizar espacios democráticos.

Se trata de un proyecto económico que invierte las prioridades que se traían del siglo XIX. Ahora se parte de la liberalización de derechos mediante una reforma educativa que buscaba la inclusión, la liberalización de cargas económicas a través de una reforma tributaria progresiva y la apertura de mercados y condiciones de

10 Manuel Quinche, Derecho constitucional colombiano, Ibáñez, 143 (2008).

11 Martha Cecilia Herrera, Historia de la educación en Colombia. La República liberal y la modernización de la educación: 1930-1946. Disponible en: http://www.pedagogica.edu.co/storage/ rce/articulos/rce26_06ensa.pdf (recuperado el 14 de julio de 2012). 
acceso, más que de competencia, bajo los lineamientos que imparta la política del Estado. Esta reforma, y su progresismo social, van a reflejar sus alcances en la expansión de diferentes sectores económicos $^{12}$. El efecto de hablar de una reforma social que se dirige a corregir inequidades de los sectores marginados hasta el momento, se verá como un catalizador en las condiciones de progreso, que se habían visto congeladas bajo la ideología económica de la Constitución de 1886.

El proyecto de desarrollo, para entonces, parte de recuperar la participación y responsabilidad social del Estado en el diseño de la política económica. Con la reforma se constitucionaliza la responsabilidad de diseñar un proyecto económico que recupere su participación en el diseño de las políticas públicas. Se parte de un sentido de solidaridad (cercano a la perspectiva progresista de la iglesia y de otros sectores sociales ${ }^{13}$ ) que debe cumplir el Estado para con los sectores más marginados. El mensaje consiste en señalar que la economía requiere de condicionamientos que le fije el derecho para acondicionarse a las realidades sociales. En este sentido, se da un giro respecto a la perspectiva de la relación entre economía y derecho en el Estado liberal durante los años 1930 y 1950. Para estos años, en la narrativa de progreso se adopta un modelo de desarrollo, que, a la par con el contexto mundial posterior a la segunda guerra, habla de la reconstrucción de las sociedades y de proyectos de convivencia social, a partir de igualdades económicas propiciadas por el esquema keynesiano, donde las economías cambian las perspectivas del modelo clásico y se empieza a pensar en términos de atención de sectores sociales y grupos poblacionales excluidos o reducidos. Esto, reflejado en el cambio de enfoque de la oferta agregada a la demanda agregada, como variable de sostenibilidad económica. El consumo, el gasto público y el ahorro ${ }^{14}$,

12 Kalmanovitz, óp. cit., 353.

13 Alberto Gómez Gutiérrez \& Jaime. Bernal Villegas, Scientia Xaveriana, Pontificia Universidad Javeriana, Bogotá, 197 (2010). En este momento el papel de la Iglesia se redirige hacia otra función. Sectores y corrientes no tradicionalistas incidirán, por ejemplo, en el diseño de proyectos educativos más incluyentes, científicos y progresistas, bajo un enfoque de responsabilidad e investigación social. Tal es el caso de la Compañía de Jesús con el reinstauración del proyecto educativo de la Universidad Javeriana y el Colegio San Bartolomé, restablecido para la década de los treinta, después de su última expulsión.

14 Alvin Hansen, Guía de Keynes, Libro III, Fondo de Cultura Económica, México D.F., 64 (1957). 
como variables definitivas para los consumidores y demandantes de derechos, ahora pasan a ser el centro de atención de los analistas económicos después de superada la crisis de la década de los treinta y el fin de la guerra.

Para 1950 las prioridades y los problemas cambiaron de referente en el panorama internacional, lo que tuvo como consecuencia que la perspectiva para abordar los proyectos educativos y las tendencias para solucionarlos no demoraron en llegar a Colombia. Ahora el contexto económico se modifica y la pregunta pasa a ser otra: ¿cómo reducir los niveles de hiperinflación que ahogan a los mercados? Esto lleva a los gobiernos de turno a atender estas necesidades ${ }^{15}$ como reacción a los aparentes excesos del modelo keynesiano. Ahora la economía se reactiva a partir de los lineamientos de Breton Woods (1944), donde se fijan condiciones para el acceso a los mercados internacionales. Se adopta para Colombia un modelo de regulación de mercados, de acuerdo a las necesidades del contexto y los mercados internacionales.

La prioridad en este segundo periodo, como se aprecia en la tabla No. 1 (1950-1974), se ve demarcada por la reducción en el compromiso y gasto público del Estado en los programas de inversión social. Durante las décadas de los sesenta y setenta del siglo XX, dan inicio los procesos de tecnocratización ${ }^{16}$ del Estado como mecanismo para hacer viable la implantación de los esquemas neoliberales en economía y hacer sostenibles las cargas adicionales que el Estado debería asumir, a partir de las responsabilidades presupuestales y el compromiso, más que económico, político por reducir los límites inflacionarios. Esto con un doble propósito: reducir la injerencia del Estado en temas como la ejecución de políticas, y delegar a los particulares y a los mercados el funcionamiento de las instituciones estatales. La libre interacción de los mercados es lo que resulta más afectado por la intervención del Estado. Los costos sociales y económicos del modelo keynesiano, se dirá en el momento ${ }^{17}$, son los responsables de las limitaciones que presentan esos mercados.

La realidad en educación no va a estar aislada de esta problemática y de su manejo. La respuesta concreta del gobierno de Laureano

15 Eduardo Galeano, Las venas abiertas de América Latina, Siglo veintiuno, 376 (1988).

16 Jairo Estrada Álvarez, óp. cit., 268.

17 Salomón Kalmanovitz, óp. cit., Cap. VII, 409. 
Gómez será la creación de Fedesarrollo, como el órgano encargado de la gestión de la política de educación, y a la vez, como un órgano de administración de recursos y gestor del proyecto educativo hacia el cual debía dirigirse el país. Es la manera de centralizar la política en educación, tanto en su diseño como en su ejecución; aislar al Estado de toda posible injerencia y dejar que los mercados vuelvan a la dinámica por sí mismos, sin la necesidad de medidas proteccionistas ni presiones inflacionarias.

Para este momento, el modelo contra-inflacionario (¿contra-keynesiano?), que podríamos denominar modelo contra-desarrollo, en el sentido que los derechos son entendidos como bienes meritorios, y de alguna manera, jurídicos, que no hacen parte de la lógica de los mercados, va a abrirse curso a lo largo de otra etapa durante los siguientes veinte años. Los mercados no deben responder por bienes que no les corresponde asignar, por cuanto se trata de "bienes" que están definidos por la ley y que por lo tanto, corresponde al derecho proveer su asignación ${ }^{18}$. La ley, como se ve en el Código Civil colombiano, adoptado durante el proyecto regenerador de finales del siglo XIX, define las condiciones en que los titulares de los derechos pueden ejercer esos derechos.

Para 1974, finales de lo que podemos denominar el tercer periodo para la política de educación, como parte de las políticas públicas económicas, se verán acrecentados los efectos de la crisis del petróleo, y con esto, la crisis del modelo proteccionista de la economía desde adentro hacia afuera, que se apoyaba en una política keynesiana ${ }^{19}$. Este momento parece marcar la caída definitiva del modelo intervencionista. La prioridad en el gasto público se dirige a garantizar un proyecto de seguridad nacional ${ }^{20}$ que implica asumir gastos inmediatos y renunciar a proyectos de largo plazo, de forma coherente con las teorías de limitación y reducción del Estado de las que hablará la política neoliberal de finales de los años setenta en el mundo y que se hará fuerte hasta inicios de la última década del

18 Rodolfo Arango sintetiza esta descripción como la relación ideal de mercados-Estados-derechos. El Estado, y por lo tanto su concepto de derechos, deben proveer los bienes que no son responsabilidad de los mercados. Esto, en resumidas cuentas, representa el institucionalismo económico y su confianza ciega en los mercados como asignadores de bienestar. Rodolfo Arango, El concepto de los derechos sociales fundamentales, Legis, Bogotá, 137 (2006).

19 Salomón Kalmanovitz, óp. cit., 318.

20 Este proyecto de seguridad va a tener una nueva aparición y fortalecimiento bajo los gobiernos Pastrana y Uribe durante 1998-2010. 
siglo XX. El Estado se reduce a su mínima expresión para conservar funciones solo en tema de seguridad, ambientadas por la necesidad de frenar la expansión del narcotráfico y el crecimiento de los grupos guerrilleros que amenazan la institucionalidad nacional. El proceso de reducción del Estado, que tiene como principal función controlar los procesos hiperinflacionarios, desplaza a variables como la inversión en educación por fuera de las prioridades de las políticas de gobierno.

Como consecuencia del proyecto de economía conservadora, que venía siendo condicionado por las políticas del Consenso de Washington, donde se sugería una economía globalizada (y unificada), se hacía necesario sentar la estructura del esquema jurídico que hiciera posible la sostenibilidad del modelo económico a largo plazo. Para empezar, se adoptaron reformas en sectores sociales con el fin de que se fuesen adaptando a las estructuras del mercado libre ${ }^{21}$. Tales sectores son, básicamente: salud, trabajo, seguridad social y educación. Había que condicionar el capital humano, reducir las cargas pensionales del Estado, así como su inversión en el sostenimiento del sector salud, con el propósito de crear mercados auto-sostenibles, para facilitar la inversión nacional e internacional en sectores estratégicos que garantizaran condiciones de expansión global y crecimiento. Los mayores beneficiados con estas medidas normativas serían el sector financiero y los sectores destinatarios de la inversión extranjera ${ }^{22}$.

El objetivo principal durante los gobiernos desde 1974 a 1990 en Colombia era claro: reducir el gasto público, con el fin de reducir el déficit fiscal ${ }^{23} \mathrm{y}$, de igual manera, reducir el tamaño del Estado en sectores estratégicos para recuperar condiciones de crecimiento. Empezaba un proceso de choque entre el Estado y los grupos al

21 Cfr. Estrada Álvarez, óp. cit., 271. Se trataba de un proceso de "administrativización” de sectores económicos para que pasasen a ser manejados o regulados por entidades de naturaleza administrativa, como parte de la rama ejecutiva. Resultado de esto, hoy en día, al inicio de cada periodo presidencial, generalmente se adopta un paquete de reformas legislativas, que van de la mano con un esquema de administración de sectores económicos y sociales. Tal es el caso de la administración Pastrana (1998-2002) con la reforma de la estructura administrativa del Estado en la Ley 489 de 1998, la reforma del gobierno Uribe (2002-2010) con la Ley 790 del 2002 y la reforma del gobierno Santos (2010-2018) con la Ley 1444 del 2011.

22 Aristizábal, Cubides \& Jiménez, óp. cit., 332.

23 Oscar Mejía \& Carolina Galindo, La tercera Corte Constitucional: tensiones y desplazamientos. El giro de la Corte Constitucional de la jurisprudencia social a la neoliberal en la Constitución de 1991, en: Intelectuales, 385. 
margen de la ley, así como el narcotráfico, que requerían dar inicio a un proceso de financiación y "ahorro" por parte de las arcas públicas. Esto implicaba el giro de un derecho social, demarcado por las reformas de la segunda mitad de la década de 1930, hacia un derecho de tinte administrativo y de gestión pública ${ }^{24}$ que organizará el andamiaje de los nuevos rumbos del Estado.

En este contexto, el Estado se aísla del intervencionismo que propusieron las reformas constitucionales de 1936 y 1945, cuya principal inspiración, sobre todo de la primera, era fuertemente social. Los mercados deberían asignar de forma perfecta los bienes esenciales evitando el aumento de los costos de transacción ${ }^{25}$ y cargas sociales que deberían ser asumidas por los mismos mercados. Para esto, requería de una plataforma jurídica que facilitara este proceso de transición, donde los mercados serán los adjudicantes de recursos y, por lo tanto, de bienestar, delimitando la participación del Estado.

Detrás de este reduccionismo del intervencionismo monetario, se busca superar la crisis económica a la que la guerra civil había conducido al país durante la década de los cincuenta, marcada por un fuerte ascenso del desempleo y la recesión, todo en un contexto de concentrada violencia ${ }^{26}$ que asentaba los focos de exclusión so-

24 Diríamos que este giro del derecho representa un choque jurídico entre las fuentes del derecho para entonces. Por un lado, que es lo que destaca para 1936, la Corte Suprema de Justicia, o la "Corte de oro", con su jurisprudencia progresista y de corte social, separada de la interpretación legalista del derecho. Por otra parte, desde 1950 hasta 1990 se llevan a cabo reformas legales promovidas por los gobiernos, que regresaron al empoderamiento de la ley como regulador de las relaciones económicas y de lo que se entendía para entonces como derecho económico, derecho de la economía y hacienda pública. Se trata de nociones más cercanas al derecho administrativo, en el caso del derecho económico y la hacienda pública, y de relaciones contractuales, para el caso del derecho de la economía. La perspectiva de la reforma de 1936 se pierde un poco de vista, en el sentido de que no se trata de un derecho que deba garantizar condiciones de progreso a partir del reconocimiento del acceso a los mercados que garantizan derechos. Sobre la discusión introductoria de las diferencias entre derecho económico, análisis económico del derecho y derecho de la economía en Colombia, cfr. Hernando Gutiérrez, Hacia un derecho económico sostenible, 96 Vniversitas Jurídica, 125 (1999).

25 Esta política, adoptada durante las décadas de los cincuenta y los sesenta en América Latina, y con particularidad en Colombia, guardaba coherencia con los políticas económicas que se importaban para aquel entonces desde los Estados Unidos, como eje del modelo neoliberal. Se trata del modelo no-intervencionista que se diseñaba por economistas para responder a las críticas y debilidades del derecho. Entre estos se destacaban los Chicago Boys, en la Universidad de Chicago, con particularidad, Ronald Coase, quien habla de su modelo de autorregulación y Milton Friedman como uno de los autores de los modelos de bancarización de las economías, como condición de crecimiento económico.

26 Salomón Kalmanovitz, óp. cit., 388. 
cial por falta de acceso a oportunidades de grupos poblacionales $\operatorname{aislados}^{27}$.

Las variables de crecimiento, tal como eran concebidas bajo el modelo keynesiano para finales de la década de los cuarenta, se ven ahora a través de un proceso de (re)cambio conceptual. Sectores tales como salud, seguridad social, trabajo y educación, a la par con otras áreas que pudiesen representar un impacto sobre las políticas de gasto del gobierno, pasan a ser entendidas como variables condicionadas a los niveles de crecimiento, que implicaba un aumento constante del PIB. Esto trae consigo que cada uno de estos sectores sea visto como bienes que se ofrecen y adquieren en mercados que funcionen de forma perfecta. La meta de desarrollo esperado (que será diferente a las condiciones de crecimiento), se alcanzaría paulatinamente, mientras la asignación de bienes, a través de los mismos mercados, fuese adecuada para fortalecer el crecimiento agregado de la economía.

En la misma línea, la liberalización del mercado se estructuró a partir de contenidos y estrategias políticas y económicas que se orientaron a generar las condiciones que posibilitan una inserción de las economías nacionales al mercado global. En suma, se trató de liberalizar y flexibilizar los mercados de bienes, trabajo y capitales, mediante: la apertura económica y comercial (libre importación y promoción a las exportaciones); reconversión industrial; estrategias de competitividad; la recuperación y el impulso de la capacidad productiva de la economía; la flexibilización laboral; la liberalización financiera (promoción a la inversión extranjera directa) y flexibilización del régimen cambiario.

En este orden de ideas, las narrativas de la modernización y de la liberalización se fundamentaron en una crítica radical al Estado de bienestar, afirmando que era el responsable del incremento del déficit, de los grandes desequilibrios macroeconómicos, de un rápido aumento de la deuda externa, y de la crisis

27 Los proyectos económicos, cuya prioridad se apoya en una visión de crecimiento económico, generalmente se orientan a financiar fórmulas de reducción del gasto público, pero el resultado, como veremos más adelante, ha implicado un costo social que incidirá en la reducción de oportunidades de grupos que no hacen parte de las políticas de turno, como lo son el apoyo a mujeres y madres cabeza de familia o niños y jóvenes que deben dejar sus estudios para convertirse en fuente de trabajo para su núcleo familiar. Cfr. Bernardo Kliksberg, América Latina. "El caso de la salud pública", en: Amartya Sen \& Bernardo Kliksberg, Primero la gente, Deusto, Barcelona, 129 (2007). 
de gobernabilidad, como consecuencia de una sobrecarga de funciones y un crecimiento incontrolable de la estructura del Estado. ${ }^{28}$

Para 1991, con una nueva Constitución vigente, aunque se trata de un modelo más ecléctico que el que propusieron los gobiernos durante los últimos cuarenta años, la estructura de mercados sigue prevaleciendo, pues son aquellos los que garantizan, de acuerdo a la lógica de la relación Estado-mercado, alcanzar las metas esperadas de crecimiento a la que aspiran los proyectos políticos.

\section{B. Un periodo coyuntural en la política económica para finales del siglo XX: la Constitución de 1991 y la educación en la economía social de mercado}

\section{La última década del siglo $\mathrm{XX}$}

Para fines de los años noventa, las políticas en educación en Colombia se ven marcadas por dos posturas que han resultado del proceso de reorganización de las estructuras políticas y sociales del país. Por un lado, la Constitución de 1991 fue concebida como un referente de transformación, que marcará la pauta para la implementación de las políticas económicas de los primeros años del siglo XXI. Con ella, se tiene una perspectiva que da vía libre a garantizar condiciones de crecimiento, al mejor estilo de la noción en la economía globalizada que se abría paso para fines del siglo XX. Los mercados se conservan como la institución preponderante, pues permiten la asignación de bienes esenciales ya que estos, dentro de una reinterpretación del discurso democrático que inspira el modelo de mercados abiertos y libertades contractuales, se convierten en espacios de interacción entre oferentes y demandantes que permiten el acceso de todos por igual a bienes esenciales. Esta parece ser, en parte, la lectura que dan algunos sobre las aspiraciones de la Constitución que acaba de ser promulgada. Otros llamarán a este proceso la constitucionalización del modelo neoliberal ${ }^{29}$.

\footnotetext{
28 Aristizábal, Cubides \& Jiménez, óp. cit., 332.

29 Édgar Novoa Torres, Restructuración, campos jurídicos y Corte Constitucional, en: Intelectuales, 378.
} 
Resultado de esto, el principio de libertad económica se fortalece, como especie de la libertad; la institución del Banco de la República como órgano autónomo del gobierno, que bajo los parámetros que defina la junta directiva, regula los cambios internacionales, en conjunción con los instrumentos bajo los cuales el gobierno regularía el comercio exterior (leyes generales en la economía), que son interpretados como herramientas encaminadas a poner en funcionamiento la estructura de mercados que tiene como fin principal reducir las presiones de déficit fiscal, un libre mercado cambiario y garantizar la libertad comercial, tanto al interior como fuera del país, lo cual optimizaba los niveles de crecimiento económico.

Por otra parte, aunque puede resultar algo paradójico, hay un giro inducido por la misma Constitución, como parte del proyecto social y económico que permite hablar de un retorno a la noción de desarrollo olvidada por los clásicos económicos y los modelos de reduccionismo estatal. Se trata de un modelo que concilia nociones de derecho, tales como: derechos fundamentales, dirección de la economía a cargo del Estado, derechos sociales fundamentales, proteccionismo, dignidad, solidaridad y progreso social, que no parecen estar muy relacionados con el proyecto económico de la liberación de mercados y la cuota de globalización por la que optan algunos sectores que interpretan a la Constitución económica.

El regreso a las nociones de desarrollo social, economía social y derechos económicos (entre otros) como bienes esenciales escasos con un alto grado de valor ${ }^{30}$, parte de un eje que se había venido aislando durante, por lo menos, los últimos cien años. Ahora, bajo el aliento de la Corte Constitucional, la narrativa que habla de la trilogía entre: mercados-servicios públicos-derechos ${ }^{31}$ se sustenta

30 Rodolfo Arango, óp. cit., 38.

31 La noción de servicios públicos esenciales aparece en la Constitución de 1991, como un instrumento del modelo de economía social de mercado que permite conciliar las relaciones de mercado con las de derechos. A través de los mercados, se garantiza la cobertura de los bienes esenciales para la subsistencia humana. La noción de servicio público esencial resulta aplicable a los que serán denominados derechos sociales fundamentales (educación, salud, trabajo, etc.). Se trata de derechos que pueden ser adquiridos bajo la libre acción de los mercados, pues reaccionan a estos incentivos, en una relación entre oferentes del bien o servicio y demandantes del derecho. El papel del Estado en esta relación será limitado pero esencial. Teniendo en cuenta la calidad de derecho social y fundamental, el Estado debe garantizar las condiciones de acceso y romper así las barreras que se generan para acceder a los mercados, tal como es el caso de estructuras de mercado como el monopolio, oligopolio y las fallas del mercado (externalidades, asimetrías de la información, etc.). En este sentido, las nociones de bienes y derechos aparecen íntimamente relacionadas, así como las condiciones de crecimiento 
en nociones y principios como solidaridad, economía social de mercado y compasión, que hablan de un retorno a la economía moral $^{32}$, y pasan a hacerse preponderantes bajo una concepción de mercado donde se asignan recursos con bajos costos, en especial para ciertos sectores poblacionales que han venido siendo excluidos por estructuras de poder de esos mercados ${ }^{33}$, que hoy se ven condicionados por los mismos límites que fija el nuevo discurso constitucional.

En este contexto, la noción de educación, al igual que otros determinantes de la demanda agregada (muy al estilo de las variables de crecimiento de las que hablaba Keynes) son tenidas en cuenta como condiciones para garantizar mínimos de desarrollo. Una vez este proceso permita una cobertura mínima de derechos y atención de necesidades básicas, se puede dar paso a un modelo de crecimiento ${ }^{34}$. Esto requerirá de condiciones jurídicas que garanticen la accesibilidad y niveles de calidad sostenible a todos los derechos en igualdad de condiciones, o por lo menos en igualdad de costos de acceso para toda la población. Esto requiere la intervención del Estado y que este recupere su papel como agente social. En un momento donde parece prevalecer la incertidumbre económica, el derecho vuelve a ganar preponderancia como reformador con una función redistribuidora de oportunidades. Una vez se alcancen

económico, ética de la economía y desarrollo social. Cfr. Amartya Sen, Desarrollo y libertad, Cap. 5, Planeta, Bogotá, (2000).

32 Los postulados de la moral económica se encontrarán, a diferencia de lo que considera un amplio sector de la doctrina económica e histórica, en los postulados de Smith. La lógica de los pilares del capitalismo smithsiano parten de la riqueza a través de los mercados competitivos, pero no se podría encontrar, en los escritos de Smith, razones para justificar la exclusión o la imposición de barreras para acceder a esa competencia y al bienestar social que esta puede llegar a producir. Al respecto Sen afirma lo siguiente: "En la lógica intervencionista de Smith, el argumento subyacente es que las señales del mercado pueden ser engañosas, y las consecuencias del libre mercado pueden significar un gran despilfarro de capital, provocado por las actividades privadas de empresas descaminadas o cortas de miras, o un despilfarro privado de recursos sociales. De hecho, Jeremy Bentham censuró a Adam Smith en una larga carta que le escribió en marzo de 1787 y en la que abogaba porque se dejara solo al mercado. Se trata de un episodio bastante notable en la historia del pensamiento económico, en el que el principal intervencionista utilitarista le da clase al gurú pionero de la economía de mercado sobre las virtudes de la asignación basada en el mercado”, ibídem, 157-158.

33 Carlos Lerma, óp. cit., 36

34 En esta tónica se mueve el discurso de la economía entendida como fuente para materializar condiciones de desarrollo, que ha sido planteada por economistas a finales del siglo XX. Entre estos se destaca A. Sen, quien parte de las condiciones de desarrollo que fije una economía como el presupuesto para que existan condiciones de crecimiento. De lo contrario, todo proceso de crecimiento que desconozca esta condición debe ser calificado como un proceso inmoral, económicamente hablando. 
condiciones de desarrollo suficiente y coherente con las necesidades de la población, se puede dar paso al diseño de instituciones económicas que permitan hablar de condiciones de crecimiento.

El papel que la Corte Constitucional asume a través de su prolífico activismo va a ser relevante y efectivo en muchos sectores poblacionales que se veían por fuera del proyecto económico iniciado a mediados del siglo XX. La Corte surge como la abanderada para la protección de la legitimidad que inspira la Constitución en materia de derechos y garantías de progreso, en medio de una crisis institucional que se expande a la misma noción de mercados, reflejado en la necesidad de responder a las fallas del mercado o poder de mercado mediante procesos de regulación e intervencionismo estatal ${ }^{35}$.

Resumiendo, se trataba de dos nociones de política económica que aparecían como contrapuestas, pero a partir de las mismas normas, artículos y conceptos económicos y constitucionales.

No obstante, pese a los esfuerzos del tribunal constitucional por fortalecer la economía social, la prevalencia de la lectura que se hacía del modelo económico como un esquema donde se hace fuerte la libertad económica y de competencia y la liberalización de los mercados hacia un esquema globalizado, evitará la maduración del proyecto social que proponía la Constitución, por lo menos en lo que a economía social de mercado correspondía ${ }^{36}$. Sectores como la educación, aunque son tratados como servicios públicos esenciales por la misma Constitución, ven esta limitante, en el sentido que siguen siendo concebidos como bienes públicos regidos por el sistema institucional de precios y mercados en los cuales el Estado debe delimitar su actuación. De esto se dará cuenta en el punto siguiente, cuando se hable del esquema de financiación que prevalece en la Constitución para el derecho a la educación. En este sentido, la última reforma estructural de la que se tiene cuenta en el sector de educación es aprobada por el legislativo mediante la Ley 30 de $1992^{37}$, adicionada por la Ley 115 de 1993.

35 En este sentido puede ver se la sentencia de la Corte Constitucional C-150 del 2003 (M.P. Manuel José Cepeda).

36 Edgar Novoa Torres, óp. cit., 377-379.

37 Para el 2012 el país, en materia de educación, viene funcionando bajo el mismo esquema petrificado que se montó en la reforma de 1992. La iniciativa del gobierno y del sector educativo en miras de un esquema jurídico renovado, puede decirse, ha sido nula. Los intentos del gobierno se han visto truncados por la misma falta de compromiso político al interior del legislativo y del sector educativo, representado por estudiantes y maestros, quienes se opusieron al último 
Parece que para finales de la década de los noventa las lecturas que se hacían de la Constitución, tanto al interior de la Corte Constitucional como fuera del mismo tribunal, generarán una tensión entre economía y derecho a través, por una parte, de la interpretación de lo que la economía clásica y los sectores formalistas del derecho ${ }^{38}$ denominan mercado libre y Estado de derecho, y, por otra parte, la noción de derechos fundamentales del que hablan modelos de economía del desarrollo y los modelos neoconstitucionales ${ }^{39}$, en el sentido de interpretar el derecho en función de garantizar libertades fundamentales y necesidades básicas insatisfechas.

\section{Las reformas constitucionales en los primeros años del siglo XXI: la financiación del modelo educativo y el regreso al esquema neoliberal}

El derecho a la educación por el que opta la Constitución de 1991 hace parte de un proyecto que apuesta por la descentralización territorial y la inversión en gasto público como factores determinantes de desarrollo. Era la influencia que el modelo de economía social de mercado proponía como respuesta de apertura frente a un proyecto educativo más incluyente, alejado del esquema centralizado de Iglesia-Estado, abierto a la recepción de un modelo educativo laico que permitía la posibilidad de otras opciones educativas por fuera del tradicionalismo de la Constitución de 1886.

Para esto, el esquema de descentralización financiera que recogían los artículos 356 y 357 de la Constitución, regulados por la Ley 60 de 1993, concebían a las entidades territoriales como el factor que permite, a través del traspaso de transferencias, asegurar condiciones de progreso, pero sobre todo, de sostenibilidad de los recursos que se destinarían para la financiación de la educación al muy largo plazo. La descentralización era mirada por el constituyente de 1991 como sinónimo de progreso. No obstante, esta perspectiva que traía la Constitución de 1991, se verá fuertemente atacada por

proyecto de reforma que planteó el gobierno del presidente Santos a finales del 2011 y que no aparecía como un proyecto consensuado ni democrático.

38 Hugo Palacios Mejía, La economía en el derecho constitucional colombiano, Derecho vigente (1999).

39 Sobre lo que puede ser una lectura del neoconstitucionalismo como una escuela de interpretación, véase: Miguel Carbonell \& Leonardo García, El canon neoconstitucional, Universidad Externado de Colombia, Bogotá (2010). 
las reformas constitucionales de inicio del siglo XXI, en lo que se refiere a reducción del gasto social, con la reducción de la variable de descentralización como factor de desarrollo, que se propone con el sistema general de participaciones, primero y mediante la incorporación del principio de sostenibilidad fiscal, después.

Sobre los efectos de estas reformas constitucionales en el proyecto de educación se volverá en la parte final del presente estudio, cuando se hablará desde una perspectiva que describirá el impacto de las mismas para la definición del proyecto de crecimiento en los inicios del siglo XXI.

\section{Contextualizando el problema: Algunas consideraciones sobre la educación en la Constitución de 1991 y el dilema entre el servicio público y el derecho social}

El choque de la Constitución de 1991 con la realidad colombiana, fue definitivo en lo que se refiere a la noción de educación. Sectores y variables económicas como la educación permitirán hablar de la relación con los proyectos de crecimiento y desarrollo. La noción de educación de la Constitución de 1991, nace en una mixtura entre lo que se entiende es la posibilidad que tiene una persona para hacer efectiva una prestación del Estado y la manera de entender esto a través de los modelos económicos, que a lo largo de las coyunturas, tal como se relató, se fueron anclando en la realidad colombiana. Por otra parte, la educación se muestra como un servicio público que requiere de una infraestructura política, jurídica y económica para que pueda prestarse de manera eficiente.

Lo que esta dicotomía parece reflejar en un primer momento, es una contradicción entre las dos nociones de educación, pero sobre todo, la manera de ver dos modelos económicos. Sin embargo se verá cómo estos modelos se hacen complementarios al momento de hablar sobre la sostenibilidad y efectividad (es decir su oponibilidad) del derecho a la educación.

Esta descripción no está muy lejos de lo que la economía entiende por bienes públicos. Se trata de los bienes que deben ser prestados por el Estado, ya que no responden a la lógica de interacción que se presenta en los mercados, por medio de la oferta y la demanda, 
y sobre todo, porque ni los mismos mercados pueden otorgarle ni medir el valor que socialmente aportan. De esta manera el modelo clásico de la economía encuentra una limitación cuando se trata de este tipo de bienes. Por un lado, aunque existe una demanda identificable de los bienes, la oferta, por otra parte, resulta limitada ya que el mercado no produce los incentivos suficientes para producirlos. Básicamente, la dificultad de fijar un precio óptimo reduce las condiciones para querer ofrecer este tipo de bienes. Sin embargo, la discusión se hace más profunda cuando de lo que se trata es de un tipo de bien público de naturaleza mixta. Existen condiciones de mercado en el que la oferta y demanda interactúan plenamente, pero otras en las que la relación no se alcanza a perfeccionar, porque los mercados han demostrado algunas de sus limitaciones.

El artículo 67 de la Constitución parece recoger esta discusión y constitucionalizar la política pública de educación, por medio de la cual se aspira a cubrir las necesidades de demanda de la misma. Al decir la Constitución que la educación es un derecho que se supedita a una función social, dice con esto que corresponde a los hacedores de políticas, responder por las limitaciones que se presenten en el mercado educativo. Se trata de un servicio público, como lo dice el mismo artículo, al que se condicionan las políticas del Estado para la prestación y regulación del servicio, pero cuyo objetivo se hace relevante al momento de calificarlo como un derecho. Esta mezcla terminológica en derecho recibe un nombre que lo califica como derecho social fundamental. En economía, cuando se hace la panorámica del problema, la noción tiende a ser la de bienes meritorios. El Estado debe desplegar su andamiaje económico para garantizar la materialización del derecho.

La obligación del Estado en este sentido, no es ilimitada pero sí permanente. La condición de ser un servicio público sujeto a los lineamientos de las políticas públicas le imprimen al Estado la responsabilidad de definir las condiciones en que se accede al derecho y crear las condiciones propicias, allí donde no lo sea, para hacer real su acceso. Su condición de ser un derecho social no obliga al Estado a garantizar y condicionar a la persona a ejercer o tomar el derecho. Dada la naturaleza de este tipo de derechos, su carácter prestacional lo convierte en una opción dentro de los proyectos de 
vida, por lo menos en lo que se refiere a la educación secundaria ${ }^{40}$. La obligación del Estado se restringe a montar un esquema de acceso al sistema educativo. Esto es lo que Amartya Sen entiende por crear las condiciones de acceso al derecho, como condición que garantiza la libertad de elección de acceder a ese derecho. Crear en la persona las capacidades (capabilities) para definir su proyecto y opción de vida.

Entonces, si se trata de un bien público en su condición original, ¿quién debe ser el encargado de suministrarlo y garantizar condiciones de calidad? La respuesta clásica sería: el Estado. Sin embargo, esta condición de bien público implicaría dos cosas. i) el servicio a la educación o el derecho, se prestarían de forma gratuita, y ii) el Estado tendría que asumir los efectos de free rider respecto a la prestación del servicio público, como consecuencia de esa gratuidad, lo que puede llevar a la reducción de las condiciones de eficiencia en el servicio. Tal parece que este no es el modelo por el que opta la Constitución; recuérdese que la misma habla de mercados, competencia, derecho de libertad económica y Estado social de derecho.

No obstante, surge otra visión que parece balancear estas posturas. En la categoría de bienes, sobre la que se viene hablando, donde se identifica a la educación como un bien público que genera una valor agregado a la sociedad y que no puede ser valorado por los mercados pero que a la vez es cubierta u ofrecida (entendiendo las limitaciones que puede traer este concepto) bajo la lógica de comportarse como un servicio público, Sen aporta otra visión que parece conciliar las dos visiones. Lo que Sen denomina un bien semipúblico permite hacer una integración entre la noción de servicio público que se ofrece por los mercados con la de bienes públicos, cuyos efectos no pueden ser valorados por las instituciones de los mercados.

También hay casos que son en gran medida mixtos. Por ejemplo, dado que la educación básica beneficia a toda la comunidad y esos beneficios pueden ir más allá de los que obtiene la persona educada, la educación básica también puede tener un componente de bien público (y puede concebirse como un bien semipúblico). Las personas que reciben educación se benefician, por supuesto,

40 Por disposición del artículo 44 constitucional, el derecho a la educación en los menores de edad es fundamental, por lo tanto, es un derecho que resulta obligatorio para el Estado. La apuesta de la Constitución es la de garantizar la educación de los menores de edad, por esto su calidad de fundamental a nivel de la educación básica primaria y secundaria, para que a partir de ahí, la persona tenga la opción de optar por un proyecto educativo. Lerma, óp. cit., 16. 
de ella, pero además, una expansión general de la educación y de la alfabetización en una región puede facilitar el cambio social (e incluso la reducción de la fecundidad y de la mortalidad, [...] y contribuir también a mejorar el progreso económico, del cual otros también se benefician. ${ }^{41}$

Ubicar a la educación bajo el argumento de los bienes semipúblicos, en la proyección que la visualiza Sen, como condición de desarrollo, habla de la preocupación del Estado para responder a las crisis de los mercados y el derecho que los regula. Cuando la educación es valorada por el valor social que puede llegar a generar, por el efecto adicional que trae consigo la ampliación en la cobertura básica, se procura cerrar las brechas de indiferencia y permitir el cambio social.

La reconstrucción histórica que se analizaba arriba permite extraer una conclusión preliminar pero básica. La historia de los mercados y de los bienes esenciales para la existencia humana, se tergiversa en muchos periodos y momentos. Colombia hace parte de estas discusiones por la prevalencia de tendencias, de acuerdo a momentos en los que se responde a coyunturas. Esta multidiversidad, delimita los alcances para poder identificar una noción clara sobre bienes como la educación e impide delimitar con claridad el papel que los mercados y los Estados deben jugar al momento de suministrarlos. Esta discusión nos lleva a un punto más general pero a la vez algo más complejo. Las dificultades sobre el papel de la economía y el derecho, cuando tratan de hablar de los mismos conceptos, lleva a hacer más difícil la reconstrucción de nociones claras donde se diferencie el desarrollo y el crecimiento. ¿Se trata de las mismas nociones? ¿Se trata de los mismos efectos y herramientas para alcanzarlas? Creemos que no y creemos que ambas pueden diferenciarse a través de esa reconstrucción histórica.

Los modelos de crecimiento económico antes de la Constitución de 1991, sobre todo los sostenidos en un contexto de economía conservadora, no se hicieron este tipo de planteamientos. Los niveles o condiciones de acceso a los servicios públicos esenciales, tal como será el caso de la educación, cuyo valor social no responde a las mediciones de los mercados, se convierten en indicadores del nivel de fortalecimiento y empoderamiento de un modelo económico.

41 Amartya Sen, óp. cit., 162. 
La lógica institucional de los mercados asume, para responder a las limitaciones del derecho, que aquellos resuelven los problemas de asignación de recursos y necesidades básicas por sí mismos. Sin embargo, esta visión entró en crisis, porque la visión tradicional de la economía entró en crisis también. Aquella lógica parece haber olvidado algo esencial. Esos mercados, como descripción de una institución en la que interactúan seres humanos, son una institución ideal ${ }^{42}$ creada por esos mismos hombres limitados.

Los mercados no están en capacidad de medir la verdadera valoración de los bienes considerados meritorios. Allá es adonde llega Sen cuando habla de la necesidad de replantear la visión tradicional de los bienes públicos y su valoración en las sociedades. Los incentivos de los mercados no permiten alcanzar una plena adjudicación de los bienes esenciales, por cuanto esos mercados no pueden medir qué tanta es la valoración que una persona hace de esos bienes meritorios. El ejemplo concreto es la educación. En bruto los resultados esperados de la educación no pueden contabilizarse ni medirse directamente como valor social en los merca$\mathrm{dos}^{43}$. Incluso, el valor social esperado que asume la noción de las externalidades positivas no refleja los efectos esperados del valor agregado de las políticas progresivas de educación.

Cuando se habla de procesos de educación, el verdadero resultado de la educación no puede valorarse en términos concretos. Una persona que finaliza un proceso de educación se encuentra capacitada para entrar al mercado laboral y ofrecer sus servicios, pero esto mismo no está representando un valor que pueda ser cuantificable en economía. Aquí se supera la primera brecha para acceder a los mercados deseados y acceder a condiciones de progreso.

El verdadero valor agregado que la educación proporciona no se encuentra solo en un mercado y en el resultado que se produce en ese mercado. El valor agregado es lo que el proceso de educación aportará en la elaboración de bienes y servicios. De aquí que la externalidad no pueda medir ese resultado adicional, pues no se trata solo de un problema de oferta reducida, sino de permitir un pleno aprovechamiento de la capacitación y los recursos que produce la educación, lo que no se alcanza solamente con cubrir en un cien

42 Rodolfo Arango, óp. cit., 138.

43 Amartya Sen, La mortalidad como un indicador, en: Sen \& Kliksberg, óp. cit., p. 84. 
por ciento la demanda de educación. Sin oportunidades de salida a los mercados, los resultados positivos en políticas de educación serían insuficientes, por no decir inútiles.

Hasta que las personas calificadas no ingresen al mercado laboral, ese valor agregado que representa la educación no puede ser contabilizado. Los resultados agregados del mercado de educación no se pueden medir de forma anticipada, porque sus resultados se verán al largo plazo. Una persona educada tiene la posibilidad de acceder a diferentes tipos de mercados, y en sí el proceso de educación-capacitación-producción, se convierte en el catalizador para la innovación y desarrollo, así como la apertura de otros mercados.

Los ingenieros que producen tecnología y registran patentes, los físicos que desarrollan ciencia, los historiadores que hacen análisis comparativo y reconstructivos, los contadores que hacen balances y sirven de garantes fiscales de las empresas, no entran en la medición de los resultados que produce su proceso de capacitación cuando esta ha concluido, en el mercado educación. Hasta aquí la economía no tiene un valor agregado en sus mercados que pueda ser medido. Hasta aquí lo que se ha materializado es la cobertura de un derecho. Su aporte, capacitación y experiencia no puede ser medido por la simple cobertura, lo que se convierte en la limitación de la externalidad. El valor agregado de la educación se mide en el resultado que produce, pero en otro mercado fuera del mismo sector educación ${ }^{44}$.

La economía clásica que hablaba del perfeccionamiento de los mercados, se ve limitada ante las necesidades más reales, pero sobre todo más cercenadas, de acceso a los bienes que suministran más que una utilidad, una satisfacción de necesidades básicas. Ahora la discusión se dirige hacia cómo medir el verdadero valor que la gente, las sociedades y los mercados, pueden dar a bienes o valores tales como la educación, el trabajo, la salud, el medio ambiente, entre otros.

Esta visión resulta algo paradójica, porque más que avanzar, lo que parece mostrar el discurso es el retorno a su punto de partida. Este era el argumento de economía social de Adam Smith, cuando hablaba de las discusiones morales y de la conciencia que se daba

44 Cfr. Andrés Oppenheimer, ¡Basta de historias!, Debate (2010). Ver prólogo. 
sobre los intereses de los demás, mediante el valor agregado que generaba el trabajo, el cual era el valor que le permitía reconocer un precio como reconocimiento justo y proporcional, tal como lo trató de explicar también Marx. Eran los fundamentos de la economía social de mercado que fueron compartidos por los pioneros de las teorías económicas en ambos extremos de la discusión sobre política económica ${ }^{45}$.

El modelo de los mercados no permite por sí mismo medir el valor real que los factores de producción pueden aportar a la gente, las sociedades y los Estados. Si entendemos a la educación como un factor de producción, o lo que podríamos decir, el factor de capital humano, no podemos determinar o cuantificar con mucha precisión cuál es el verdadero valor agregado que educar produce en el mercado. No se puede anticipar, cuantitativamente hablando, cuál es el aporte que una persona educada entrega a la sociedad. Se requiere, por lo menos en una instancia inicial, de lo que puede denominarse como el conector de la educación con la fuerza productiva de una sociedad. El valor que la educación trae solo puede reflejarse de manera agregada cuando se miden los resultados de los proyectos educativos. Es decir, cuántos escolares pueden ingresar a la educación secundaria; cuántos profesionales entran a producir en los diferentes mercados; cuántos doctorados producen resultados de investigación que son adoptados por el sector productivo de la economía y cuáles, por otra parte, se convierten en aporte directo a los mismos programas educativos o incluso a los procesos de producción pública o privada.

A partir de aquí, en educación la pregunta a la que arribamos y que procuraremos responder, puede formularse de la siguiente manera: ¿Cómo se hace posible identificar el valor adicional que genera la educación, pero que los mercados no pueden medir? Para responder, en la segunda parte de la investigación partiremos de la tesis de la que parte Amartya Sen, en la cual el servicio a la educación debe ser entendido como un bien semi-público. Esto implicará que no sea entendido como un bien gratuito que debe ser suministrado exclusivamente por el Estado; no obstante, las

45 Los argumentos de una ética para la economía eran rescatados como oposición a los argumentos que daban una primacía absoluta al concepto de mercados en su noción clásica. Cfr. Sen, óp. cit., 154. 
condiciones de mercado para un bien de esta naturaleza requieren condiciones de una economía social de mercado. 


\section{PARA CONCLUIR}

Las condiciones de crecimiento que se esperan de una economía dependen de forma muy directa de la menor intervención y creación del derecho. La efectividad de los modelos de economía liberal, en esta medida, depende de la mínima participación del Estado.

La tendencia en el diseño de la política económica, y junto con ella de la política educativa, muestra una preponderancia, sobre todo en los últimos cuarenta años, por la prevalencia del modelo liberal de mercado para la asignación del derecho y el cubrimiento de la demanda de educación en el país. Este modelo retornará con fuerza para el 2001 y el 2011 a través de las reformas constitucionales.

La misma Constitución, por su naturaleza y origen democrático, da cabida para que se hable de condiciones de mercado, competencia y servicio público, como características del modelo educativo que funciona en Colombia. Sin embargo, existe un obstáculo que está impidiendo el pleno funcionamiento del mercado, o lo que sugiere la Corte Constitucional durante su primera década de funcionamiento, se requiere de un modelo de regulación que intervenga el mercado a la educación porque la naturaleza del derecho lo exige así.

El costo social que se ha generado en el mercado a la educación, como especie de derecho social fundamental, en los términos que lo señala Rodolfo Arango, ha sido muy alto. El problema, representado como falla del mercado de la educación muestra el periodo de crisis que afronta la teoría de los mercados para inicios del siglo XXI, a modo de externalidad positiva. Este costo social, a modo de precio en el mercado, se ha trasmitido, en especial para las clases menos favorecidas.

Hasta aquí resultaría apresurado concluir que la educación hace parte de lo que se entiende por un proyecto de desarrollo y no de un proyecto de crecimiento o viceversa. Lo que sí es claro es que para inicios del siglo XXI, estas dos nociones son diferentes porque implican dos maneras diferentes de entender la economía que esperan resultados distintos. Su contenido ideológico termina por marcar los rumbos de los proyectos de política económica, $\mathrm{y}$ 
con esto el presente y futuro del modelo educativo del que se habla en Colombia.

Las respuestas de ambos, en los periodos de crisis económicas, no son iguales. Ambos muestran formas, prioridades y mecanismos de afrontar los periodos de recesión de diferente manera. Ambos tienden a dar una explicación a sus políticas dependiendo de la coyuntura, renunciando a unas variables a favor de otras. En este proceso histórico de tensiones, los modelos de crecimiento económico que han prevalecido en las esferas de las economías latinoamericanas y en Colombia, durante finales del siglo XX e inicios del siglo XXI, en concreto durante los gobiernos desde 1994 a 2014, marcan una tendencia a aislar la atención sobre su importancia. Dicha tensión y las reformas constitucionales que la acompañan serán analizadas en la segunda parte de esta investigación que se expone al lector. 


\section{REFERENCIAS}

Alberto Gómez Gutiérrez \& Jaime. Bernal Villegas, Scientia Xaveriana, Pontificia Universidad Javeriana, Bogotá (2010).

Alvin Hansen, Guía de Keynes, Libro III, Fondo de Cultura Económica, México D. F. (1957).

Amartya Sen, Desarrollo y libertad, Planeta, Bogotá (2000).

Andrés Oppenheimer, ¡Basta de historias!, Debate (2010)

Bernardo Kliksberg, América Latina. "El caso de la salud pública", en: Amartya Sen y Bernardo Kliksberg, Primero la gente, Deusto, Barcelona (2007).

Carlos Alberto Lerma Carreño, El derecho a la educación en Colombia, Fondo latinoamericano de políticas educativas (2007).

Édgar Novoa Torres, Restructuración, campos jurídicos y Corte Constitucional, en: Jairo Estrada Álvarez, ed., Intelectuales, tecnócratas y reformas neoliberales en América Latina, 378, Universidad Nacional de Colombia, Bogotá (2005).

Eduardo Galeano, Venas abiertas de América Latina, Siglo veintiuno (1988).

Hernando Gutiérrez, Hacia un derecho económico sostenible, 96 Vniversitas Jurídica, 125 (1999).

Hugo Palacios Mejía, La economía en el derecho constitucional colombiano, Derecho vigente (1999).

Manuel Quinche, Derecho constitucional colombiano, Ibáñez (2008).

Martha Cecilia Herrera, Historia de la educación en Colombia. La República liberal y la modernización de la educación: 1930-1946. Disponible en: http://www. pedagogica.edu.co/storage/rce/articulos/rce26_06ensa.pdf (recuperado el 14 de julio de 2012).

Miguel Carbonell \& Leonardo García, El canon neoconstitucional, Universidad Externado de Colombia, Bogotá (2010).

Rodolfo Arango, El concepto de los derechos sociales fundamentales, Legis, Bogotá (2006).

Salomón Kalmanovitz, Economía y nación. Una breve historia de Colombia, Norma, Bogotá (2003).

Ugo Pipitone, Ciudades, naciones, regiones, Fondo de Cultura Económica, México D.F. (2003). 
